\title{
Five Canadian College Libraries
}

Mr. Redmond is acting librarian, Nova Scotia Technical College, Halifax.

CanadA's four eastern provinces support $\mathrm{J}_{2 \mathrm{I}}$ institutions of higher education. Of these, four privately supported colleges and one provincial university listed below, together with nine small Catholic colleges, are the principal institutions: Dalhousie University and the University of King's College, Halifax, Nova Scotia ; Acadia University, Wolfville, Nova Scotia; Mount Allison University, Sackville, New Brunswick; and University of New Brunswick, Fredericton. In 1947 a study of these five college libraries was proposed as a thesis project.

These universities are based principally on colleges of liberal arts and sciences with enrolments of 1000 or less, and faculties of 40 to 60 . The libraries range from 30 to 90 thousand volumes, with staffs of three to I2. Dependent, save for New Brunswick, chiefly on endowment income and student fees, members of the group have generally similar objectives, curricula, administrative organization and problems. It was reasonable to suppose that their libraries would have a general resemblance and common problems.

Although the college libraries had been mentioned in various surveys of education, they had never been studied in detail. The project was undertaken as a study of basic organizations and resources, usable by individual libraries as a basis for detailed local study and regional collaboration. An alternative would have been to examine a 1 Based on an M.S. thesis prepared at the University
of Illinow Library School, 1949. single aspect, e.g. library resources throughout the region-a project perhaps less needed in view of present Canadian library developments.

Obvious major aspects of college libraries were those suggested by Shores, and treated for planning purposes as: (I) budget; (2) personnel, (3) book stock, (4) physical plant, (5) organization and administration, and (6) library use or "educational participation." 2 To these was added historical background, in order to develop the suspected pattern of similarity in institutional and library problems.

The oldest of these colleges was founded in the 1780 's, others on through 1840 . They had libraries of a sort almost immediately, but none more than 5000 volumes until after 1900. Befitting denominational colleges, as were all except Dalhousie, their early libraries leaned heavily to theology, classics and history. Faculty members were the voluntary part-time librarians until the last three decades; all of the few hundred dollars occasionally available went for books. Libraries were open a few hours each day or week, as the custodian might have time. By 1915, administrative and physical changes had begun. Two new library buildings were opened, and fulltime librarians (one trained, one untrained) appointed. Card catalogs were written, and classification superseded fixed location. The same process occurred at another college about 1925, at the two others in the early I930's. Faculty members retained administrative control, either

2 Shores, Louis. "Evaluating Library Service to Higher Education." College and Research Libraries, 2:21 I-I5, June 1941. 
as titular librarians or through committees, even after full-time trained staffs (usually only one person) were employed. Salaries remained pittances. The 1920's were the era of special collections, almost every library acquiring a large grouping from some generous donor who usually added restrictions or took continuing control over the material. Some of these were special subject collections, e.g. Canadiana; others were "hobby" collections of slight use to the recipient libraries.

The third or active era for these college libraries came about largely because of the World War II and the tide of veteran students, beginning in 1944 and reaching its peak in 1947. Some changes had been seen as early as the mid I930's, when, after Carnegie Corporation of New York surveys of education in the Maritimes and of libraries in Canada, college libraries received several grants from philanthropic foundations. Valuable as it was, this aid could not meet the situation fully, and only high postwar enrolments swelling all university activities raised library budgets above bare existence levels.

\section{Finances}

The A.L.A. Classification and Pay Plans were used as a comparison standard, though Canadian conditions required adjustments in scales. The five libraries included one Class I, two Class II, two Class III, and one Class IV; but except for the government supported University of New Brunswick, the actual salary budget in each case was half or less of the adequate level, while expenditures for library materials were one third of the recommended amount. In the privately supported colleges, library support amounts quite uniformly to \$I 2-\$I 5 per student. Owing to variations in parttime and affiliated teaching staff, the figure for library support per faculty member is less significant, ranging from $\$ 200$ to $\$ 400$.
The source of this support varies. The most highly endowed institution, Dalhousie (endowment $\$ 5500$ per student), appropriates library funds principally from general income, while some church colleges depend principally on special endowments for book funds. Mount Allison also includes a direct \$IO student library fee.

Staff establishment and salaries are quite separate from the official "library budget." The library committee, usually all faculty members but in one case including also the president and two members of the governing board, allots the book funds. Staff needs are usually passed on by the university administration as they arise, and salary scales have been set up only at New Brunswick, where all staff policies are kept in line with general provincial civil service policies. At other colleges, understaffing and a policy of "private bargaining" about salaries has prevailed.

The basic Canadian salary for professional librarians in 1948 , as determined by the Canadian Library Association, was \$1800; the minimum salary in the Dominion government Civil Service scale in 1949 was $\$ 2$ I00 for the same position. The present study developed and recommended a scale based on $\$ 2100$, rising through three grades to a basic salary for the highest grade of $\$ 3600$, which is the prevailing basic salary for academic staff having the doctoral degree (based on Dominion Bureau of Statistics figures for 1944-46). Of the college library salaries investigated, only three were above $\$$ I 800 ; Io reached that level and six were below. Figures for teaching staff in the same colleges showed that librarians received one half to two thirds the salary of the average assistant professor, or about four fifths of the minimum for library assistants in the U.S. Even these levels were reached only after I940; before that, the general salary level was on the order of $\$ 1200$. There is still 
no general policy of salary schedules and increases.

Policy on allotment of book budgets varies widely. The college with the largest budget reserves more than half of it as a general fund, supervised by the faculty book committee. The next largest budget is 90 per cent divided into departmental allotments. The smaller book funds are divided about 75 per cent to departments and 25 per cent as general funds. From other considerations it appeared that those libraries operated as strong, independent departments, with capable administration and recognition from university policy makers, were left direct control of a much larger proportion of the book funds than libraries where faculty control has a long and heavy tradition, where administration has been weak and dependent on faculty direction.

It is difficult to say to what extent these levels of library support are "adequate," because university policy on the library is uniformly vague. Present understaffing, however, indicates that a 50 per cent increase in salary budgets is imperative; doubling would be needed to reach recommended levels. The haphazard book resources to be mentioned presently, the lack of services and general interest in the library, indicate that the same proportionate increase in book budgets would not be excessive.

McEwen's gloomy picture of the small college librarian ${ }^{3}$ is not duplicated in this region; yet through personal relationships in the small academic community, the academic attitude is frequently scornful of the library staff, consciously or otherwise. Especially where faculty control, unofficial or through a committee, persists, the library staff are considered clerks and the library is a depot, not a service. At only one college is the librarian a recognized faculty

3 McEwen, R. W. "Status of College Librarians." College and Research Libraries, 3:256-61, June 1942. member; here he also teaches library science. One college continues with a part-time professor librarian. Another has an unusual organization with an "honorary librarian" who is dean of arts and head of a teaching department, as administrative chief while the librarian is operating head. A fourth college library has no actual librarian, the associate librarian carrying on operating functions while administrative functions are in the hands of a joint faculty governors committee. In all these colleges the "library clerk" attitude persists, even though the title of faculty member may be given to staff members.

Although one librarian declared that "Unanimity is needed among Maritime librarians in regard to faculty status for library staff," the question lies dormant, probably because few library workers are qualified or feel the need of such recognition. Of the library staffs surveyed, those workers with more than five years' experience uniformly had either a diploma course or no formal library training. Only one head librarian in the group had a library science degree, though others had long experience. The remaining staff consisted of young workers with only a year or two of experience, and with bachelor's degrees in library science. The turnover among this group is very high. One library has changed its whole staff almost every year. Salaries, understaffing and outside control seem to encourage the turnover.

Small staffs of two to eight professional workers cannot effectively be departmentalized, since almost everyone must aid in circulation. Two libraries have special order clerks and reference librarians. One also has an archivist and a serials librarian. Catalogers frequently do their own typing. There is little specialization in interests or duties, except for the cataloger, and the region is not developing either specialized workers or administrators. Most serious, 
this lack of professional development does not encourage confidence and respect from faculty members or library staff, and abases salary standards. Within the region as a whole, poor precedent between institutions, and lack of professional leadership result. This is reflected also in the professional affiliations and reading habits of these librarians. Only Io out of $I 7$ are members of the Canadian Library Association, and two of A.L.A. Only nine regularly read Library Journal or Ontario Library Review, only eight read College and Research Libraries. There is little acquaintance with the literature of modern librarianship.

\section{Library Resources}

The 1943 checklists of the North Central Association were used as a quantitative measure of library book stocks. The more than 300,000 volumes in five libraries contain collections of possible research caliber in five fields - theology, history, Canadian literature and history, English literature, and biological science-resources in a relatively limited field sufficient for original work at the M.A. level. None of the colleges offers a Ph.D. (Dalhousie offers medical and dental doctorates), but the work for the M.A. is sometimes being offered where library holdings are hardly adequate for undergraduate work.

Special or outstanding collections are isolated, one or two in each college, typical of the college library which cannot afford research collections. ${ }^{4}$ Further, seven important fields-French and German literatures, general language and literature, general science and mathematics, forestry (although a master's degree is given), technology (despite an engineering school), and general bibliography-are nowhere adequately represented in these libraries for their curricular importance. Nor are sev-

\footnotetext{
4 Downs, R. B. "Where Are America's Research
} Downs, R. B. Wrientific Monthly, 62:513, I946.
Resources?" eral of these subjects adequately covered by any other library in the region. Yet honors or advanced degrees are offered in several of them.

Three of the best collections moreover, have been built up accidentally, or outside curricular demands, by outside donors. Many such special collections are very little used.

Inadequate library administration and shortsighted institutional administration are largely responsible. Only when some faculty member was immediately interested has the library been intensively cultivated; and the faculty, sometimes belittling the importance of library resources in their own specialty, have offered courses and degrees without adequate library support. General or borderline fields have particularly suffered. It is the librarian's duty to buttress holdings where required, particularly in basic fields like bibliography, and to "sell" the library to the faculty-to persuade them fully to exploit special library resources, whether obtained accidentally or through philanthropy. Above all, special collections must not be left unmaintained or, like several of these, they become useless corpses.

Best use can be made of available resources and funds only if these libraries cooperate and combine; first by pooling and listing of resources, second by specialization in acquisition and growth, and third by intensive and cooperative use. A regional union catalog, long discussed by the Maritime Library Association, was shelved in 1949 in favor of awaiting the proposed Canadian national union catalog. The published catalogs of certain special collections are insufficient to allow full use of the entire library, especially when no one library has an outstanding or complete collection. "Family pride" has been the greatest obstacle to specialization and pooling of resources. Yet regional resources in a given subject could in many cases be com- 
bined to give a single collection of graduate caliber, without impoverishing any one library.

In short, institutional policies as well as library policies have made these college libraries haphazard and ineffective. Longterm development in well-defined directions is required, with inter-institutional agreement and avoidance of duplication, in order to make best use of meager funds.

\section{Physical Plant}

Ironically, the least crowded library building is the only one to be expanded. At New Brunswick, a growing 40,000 volume library is well housed in a building with a total book capacity of 125,000 , with facilities for microfilm, archives, special collections and a possible library school. King's College library, in a I93 I building, will never outgrow its quarters because of its ancillary position to Dalhousie and related libraries. A third library, in a 1927 building, requires more stack space and better utilization of space originally conceived as memorial halls and board rooms. Two libraries in 1915 buildings have far outgrown them.

The undesirability of nonlibrary functions in a library building has been well demonstrated here. Whether offices or classrooms, they stay long past the original "temporary" arrangements, and space finally released for library purposes frequently proves insufficient for the needed expansion. It is impossible to plan far enough ahead for a college library. Mechanization is one of the greatest needs in these buildings now. Ill-designed buildings with several floors need electric booklifts, elevators and communication systems. Next, possibly of even more importance, is modern lighting and sound conditioning.

\section{Library Use}

Even in a surface appraisal of these college libraries, library use seemed more important than even actual library resources, and it was equally apparent that annual reports or "monthly circulation statistics" gave no indication of real library use. There was more than a suspicion that a "clique" makes most use of the library, and statistical study of actual circulation transactions was commenced. Call slips or equivalent records of single transactions were accumulated in each test library for a given period, usually four weeks. For each type of circulation (overnight reserve, in-building reserve, and nonreserve), the set of slips was arranged by borrower's name and a frequency distribution obtained, listing number of borrowers against circulation in books per student month. Loans to faculty, nonstudents and graduate students were excluded. In March I 948 two libraries supplied four files of slips; in February-March I 949 three libraries supplied eight files, a total of nearly 5000 single loans.

No matter what type of circulation was examined, distribution among light and heavy users for any one month was consistent. Differences from the typical curve were not statistically significant. Seventy five per cent of the students make no loans from the library in a given month; Io per cent borrow one book ( 14 per cent of total circulation); 5 per cent borrow two (also I 4 per cent); a further 6 per cent borrow five or more books each per month and account for 45 per cent of total circulation. "Mean" circulation per student month for nonreserves is I.2, for reserves 0.6 ; standard deviation of the arithmetic mean, 2.2. Median nonreserve circulation was 0.7 , and slightly lower for reserves. These figures agree well with Branscomb's " 12 books per student year" but reserve circulation appears much smaller than his 50 to $60 .^{5}$

Branscomb, Harvie. Teaching with Books. Chicago, American Library Association, 1940, Chapter 2. 
There is considerable doubt whether open shelf reading makes up the difference.

At Dalhousie, a nonresidential college in a city of 100,000 , much higher reading room and overnight use, totaling twice the mean nonreserve use, indicated the problem of the nonresident student who frequently cannot return to the library during the evening. Overnight loan privileges start at 4:00 P.M. Nonreserve use appeared normal, but in-building use was one and onehalf times larger than nonreserve, and total library use per student was much higher. Competitive attractions of urban life are possibly less conducive to evening and weekend study, periods when the two-week books would normally be most used. At Dalhousie only 602 of the 1259 students were in arts, and the distribution of library use was much nearer the normal type when only they were considered. Departmental libraries and nearby King's College actually reported more outside students than its own students using the library at some times. Insufficiency of reading-room space and other facilities may also be a factor.

The heaviest users are arts seniors, mostly taking honors. One library showed an exception, the heaviest users coming from all years and all courses. It was quite noticeable in all cases that there are both arts seniors who never use the library, and occasional students who use the library heavily regardless of their course interests. No investigation was made of curricular reading in this regard. However, low Pearson correlations were found between various types of service (about -.12), and the pattern of recurrence of names in various files of call slips indicates that the individual borrower frequently uses one or two types of service almost exclusively, though his preferred combination may not follow a general rule.

Reserves were generally agreed to be an unsatisfactory situation but one interesting effect was noted when, between the 1948 and 1949 survey periods, one college almost abandoned the strict reserve system in favor of three-day loans for entire subjects. All books in English composition, for example, may be put on three-day or 48 -hour circulation. Under this system, 550 of the 966 nonreserve loans in the 1949 test period were three-day loans, made by 208 borrowers, and many renewed. Total circulation did not significantly increase. The scatter and correlation with other types of circulation was not significantly different between three-day loans and all nonreserve loans. More important was the indication that nonreserve book use is mostly course work, and that many two-week loans are probably substitutes for unavailable reserve books. It also hints that books borrowed for two weeks are often not read through or thoroughly. Although total library use has not increased, the availability of collateral reading material and the use of "course reserves" has probably increased.

Stagnant reserve lists, unused titles, overloaded reserve shelves, and failure to adjust copies on hand to student load are the common complaints about reserve work. The experience of substituting short loan for strict reserve circulation indicates that "collateral" rather than "required" reading, larger backgrounds of material and freer choice are factors in easing library loads, but total reading will not increase until teaching methods are radically altered.

Lack of reference service, or of student demand for such aid, is a surprising phenomenon in all the libraries. Only two of the group have reference librarians. In one library, the reference librarian has over-all supervision of public service functions, circulation (in an open-stack library) being an entirely clerical department. In the other library, the reference librarian has general charge of periodicals and government documents. One of the other libraries reports 
that "little formal" reference work is done, and assistance to individual students is almost entirely aid in using the catalog. Nor does this library give any instruction to the general student body in the use of the library. In all the libraries, desk attendants are usually clerical, and neither students nor faculty seem fully to realize the services available from trained library staff. The conclusion was inevitable that this is one of the perpetuating factors in the library clerk attitude in the minds of faculty and administration. Though local circumstances make applications vary, increased emphasis seems needed on public service, and particularly special bibliographic and reference service to the faculty. Bolstering of the quality and quantity of reference and bibliographic resources in the library is an immediate need.

The Acadia Library offers elective courses in library science for undergraduates; the enrolment is very small. New Brunswick reports very marked and immediate gains in use of the library after inauguration of a compulsory lecture and tour of the open-stack library for all new students, sometime after the opening of classes each fall. A third library had had negligible results from an annual tour of the library for new students during "orientation week" each fall, and in 1949 opened a compulsory four lecture course in use of the library, beginning a few weeks after the beginning of classes. Some faculty members at various colleges have been suffciently interested in the bibliography of their subjects to give, or enlist library staff in giving, lectures on subject bibliography, but these have never been directed thoroughly or consistently at advanced students writing theses.

The conclusions reached from the necessarily limited study of circulation were far from encouraging. They showed that only one fifth of the student body are regular users of the library, and that the usual "statistics" of "circulation" are useless. The attempts at analysis indicate that a single record of each loan transaction is sufficient, provided it is a transaction record, i.e., a one-time-use call slip (or better, light card). It is better adapted to college library needs than a bookcard system because records can be saved and accumulated for study. College library methods, services and resources should be based on direct study of these records by statistical analysis.

Primary stress falls on different types of circulation in the various institutions, dependent on such factors as student residence circumstances, but generally nonreserve books must be available freely, without difficulty or delay, to the undergraduate. The best or most pertinent readings in connection with courses must be suggested and made available without restrictions of time or location.

The student must be aided not only with difficulties of obtaining material, but of selecting and using it, and the student must be trained to perform these functions for himself. This involves, first, availability of books-open stacks or shelves. The popularity of a tiny college library with 5000 books, the major part of its newest material on open shelves, and the popularity of a larger open-stack library, both demonstrate this. Secondly, the short-loan system replaces strict reserves, and finally, cooperation of library and teaching staff to aid students in selecting material, and to teach library habits, will increase the real use of these libraries.

\section{Conclusion}

Feasibility was set as a hard limit in this survey of college libraries. Conclusions and recommendations, in a relatively poor group of institutions, are useless unless they can be carried out within existing financial structures. The vicious circle would be 
impossible to break if this were taken literally. One college indeed refused to break it when they refused to accept a trained librarian at a salary of \$2500. They have since not had a head librarian, and have operated under administrative direction of a faculty committee.

The vicious circle in many of these libraries must be broken at the point of university administration, in order that new concepts of library service may be developed. The supervising body, whether board of governors, president, or faculty committee, must be convinced, whether by the library staff or other agency, of the service which a library can offer when operating under a capable administrative specialist. It would then be the administratorlibrarian's task to convince the faculty in general and win their cooperation in a program of welding the library to the instructional work. Unfortunately, the supply of capable librarians, of academic standing equal to the faculty, and with experience in library administration is particularly limited in eastern Canada. "Persuasive personal relationships," however, would make expensive library programs perhaps less necessary. Joint faculty library approach is essential if the library is to be an active and essential part of the student's education.

The other aspect of the problem is regional, and here again personal relationships, and the continued health and prosperity of regional library associations, will accomplish much. Nevertheless, some actual institutional cooperation, relinquishment of sovereignty even, will be needed to make the librarians' task possible.

\section{The Vassariana Collection}

\section{(Continued from page 3.54)}

both of these series constantly, for each new gift of Vassariana brings some item hitherto lacking in our collection. As a final "last resort" we have an information file for ready reference. This includes not only items of information, but also location notes and statistics.

As for the physical care of the collection, books and pamphlets are cared for in the usual way, being protected by leather or cloth bindings, lacers, binders, envelopes or pamphlet boxes. Oversize broadsides, maps and charts are stored in large poster boxes, protected by folders of acid-free paper. The archival materials in the vault have special shelving, lockers and cupboards. Fragile items which need extra protection are placed in cellophane envelopes or acid-free folders. We buy 100 per cent rag content paper, substance 13 , in sheets $28^{\prime \prime} \times 34^{\prime \prime}$ and cut them to the desired size. Many of the rarer items have been restored and repaired; some are mounted on silk, others on linen or photomount. In our experience the lamination process has not been successful.

Since the library is the official depository of college publications, we have worked out a plan for the storage and arrangement of extra copies. After some experimenting we decided to arrange the items by call number. An author index in slip form gives the exact location, the number of copies available and any special notes about scarcity or other restrictions. A student assistant records items and keeps the collection in order.

We have a definite program for the reproduction of unique and fragile items. Copies are made by photography, including microfilm and portagraph, and typescripts are made whenever advisable. For example, we plan to copy all of the manuscript letters of Matthew Vassar. The collection of typescripts will then be cataloged to serve the need of the student who is interested in content only. At present we have not the necsary funds or the personnel to carry the program forward as rapidly as we would like. A Vassariana endowment is greatly needed. 